\title{
Seed germination of Solanum spp. (Solanaceae) for use in rehabilitation and commercial industries
}

\author{
L.E. Commander ${ }^{\mathrm{A}, \mathrm{B}, \mathrm{E}}$, D.J. Merritt ${ }^{\mathrm{A}, \mathrm{B}}$, D.P. Rokich $^{\mathrm{A}, \mathrm{B}, \mathrm{C}}$, G.R. Flematti ${ }^{\mathrm{D}}$ and K.W. \\ Dixon $^{\mathrm{A}, \mathrm{B}}$ \\ ${ }^{A}$ Kings Park and Botanic Garden, West Perth, WA 6005, Australia \\ ${ }^{\mathrm{B}}$ School of Plant Biology, Faculty of Natural and Agricultural Sciences, The University \\ of Western Australia, Crawley, WA 6009, Australia \\ ${ }^{\mathrm{C}}$ School of Environmental Science, Murdoch University, Murdoch, WA 6150, Australia \\ ${ }^{\mathrm{D} S c h o o l ~ o f ~ B i o m e d i c a l ~ a n d ~ C h e m i c a l ~ S c i e n c e s, ~ T h e ~ U n i v e r s i t y ~ o f ~ W e s t e r n ~ A u s t r a l i a, ~}$ \\ Crawley, WA 6009, Australia \\ ${ }^{\mathrm{E}}$ Corresponding author: lucy.commander@bgpa.wa.gov.au
}

Abstract. Effective methods for propagation of native Solanum species are required for mine rehabilitation and the native food industry in Australia. This study investigated seed germination of eight native Solanum species with respect to incubation temperature and the efficacy of germination promoting compounds gibberellic acid $\left(\mathrm{GA}_{3}\right)$, the butenolide isolated from smoke (karrikinolide, $\mathrm{KAR}_{1}$ ) and smoke water (SW). Seeds of all species were tested under a temperature regime of $26 / 13^{\circ} \mathrm{C}$ or $33 / 18^{\circ} \mathrm{C}$. In these conditions, seeds of only two species, S. cunninghamii Benth. and S. phlomoides Benth. germinated to high levels without treatment. Of the remaining six species, $\mathrm{GA}_{3}$ alone promoted germination in S. chippendalei Symon, S. diversiflorum F.Muell. and S. sturtianum F.Muell., whilst $\mathrm{GA}_{3}, \mathrm{KAR}_{1}$ and $\mathrm{SW}$ were effective at promoting germination of $S$. centrale J.M.Black, $S$. dioicum W.Fitzg. and S. orbiculatum Dunal ex Poir. to varying degrees. Additional incubation temperatures $\left(10,15,20,25\right.$ and $\left.30^{\circ} \mathrm{C}\right)$ were examined for $S$. centrale and $S$. orbiculatum. For both species, broadly similar patterns were noted in the response of seeds to $\mathrm{GA}_{3}, \mathrm{KAR}_{1}$ and $\mathrm{SW}$ across all temperatures. However, for $S$. centrale seeds, germination percentages were higher at $26 / 13^{\circ} \mathrm{C}$ than at any of the constant temperatures, and there was a trend of increasing germination with increasing constant temperature for S. orbiculatum seeds. Analysis of seed embryo type and imbibition characteristics and 33 consideration of the subsequent germination results indicates that dormant Solanum seeds 4 possess physiological dormancy. 


\section{Introduction}

2 Solanum species occur across many ecosystems and in all continents. The genus

3 includes economically important food crops such as potato (Solanum tuberosum) and

4 eggplant (Solanum melongena). There are 47 native species of Solanum in Western

5 Australia and 11 naturalised species (Paczkowsa and Chapman 2000). Many of the

6 native species, commonly know as bush tomatoes, were used as a food source by

7 indigenous Australians and a number of species are in commercial production or

8 evaluation as bush tucker. Edible Solanum species, including S. centrale (Latz 1995;

9 Stefaniski 1998; Ahmed and Johnson 2000) and S. chippendalei (Courtenay pers.

10 comm.), are important food sources with fruits possessing high carbohydrate and vitamin

11 C content.

13 While the fruit of $S$. centrale and S. chippendalei can be collected from the wild,

14 commercial production of S. centrale is underway (Ahmed and Johnson 2000) and is

15 planned for S. chippendalei (Courtenay pers. comm.). However, information about

16 propagation is required. Also, propagation of Solanum species is required for minesite

17 restoration in Australia, particularly as a result of a resurgence in mining activity in the

18 arid zone where the genus most commonly occurs. Species required in restoration

19 include $S$. orbiculatum and S. diversiflorum as both species are common and widespread

20 components of the pre-mined vegetation. However, little is known about the seed

21 germination biology of arid zone vegetation in Australia, particularly with respect to

22 methods applicable to large scale propagation and restoration. Furthermore, poor seed

23 germination and limited horticultural information available on Solanum species are

24 hampering propagation and commercial production.

26 The two studies published on $S$. centrale seeds indicate that gibberellic acid $\left(\mathrm{GA}_{3}\right)$ and 27 smoke may be useful germination promoting agents for Solanum spp. (Stefaniski 1998;

28 Ahmed et al. 2005). Stefaniski (1998) found gibberellic acid increased germination from

$297 \%$ to $20 \%$ while Ahmed et al. (2005) showed that a combination of seed-coat nicking

30 and aerosol smoke improved germination. In particular, fire related cues warrant further

31 investigation as disturbance by fire has been observed to encourage the spread of

32 Solanum species in natural ecosystems (Latz 1995). Smoke products are well known to

33 promote germination of a large number of Australian species (Dixon et al. 1995; Roche

34 et al. 1997) and the newly discovered active chemical in smoke, the butenolide (3-

35 methyl-2H-furo[2,3-c]pyran-2-one) (Flematti et al. 2004), now known as karrikinolide 
$1 \quad\left(\mathrm{KAR}_{1}\right)$ (Dixon et al. 2008), has proved highly effective at promoting germination of a

2 broad range of Australian species, including arid zone species (Merritt et al. 2006).

3 Gibberellins are similarly known to be efficacious across a broad range of Australian

4 species (Bell et al. 1995; Plummer and Bell 1995) and are thought to act via mechanisms

5 that include promoting the growth potential of the embryo (Kucera et al. 2005),

6 weakening endospermic cells (Groot and Karssen 1987; Groot et al. 1988; Debeaujon

7 and Koornneef 2000), and replacing after-ripening requirements (Baskin and Baskin

$82004 a)$.

10 Optimal germination temperatures for seed germination usually correspond to the time

11 where water is non-limiting in the environment (Bell et al. 1993; Bell 1999; Bell et al.

12 1999). The distribution of the Solanum species in this study covers a range of

13 environmental conditions from wet summers and dry winters (Pilbara, Great Sandy

14 Desert and Dampierland regions), to an arid region with aseasonal rainfall (MacDonnell

15 Ranges in central Australia) and finally to areas that receive sporadic winter rain and

16 occasional summer cyclonic systems (Geraldton Sandplains and Murchison regions). As

17 these regions receive summer rainfall, it is likely that incubation temperatures

18 corresponding to the season of reliable rainfall may be higher than typically used in

19 nursery propagation of Australian species in southern Australia (15-20 $\left.{ }^{\circ} \mathrm{C}\right)$ (Bell 1999).

20 For example, Jurado and Westoby (1992) found that germination of a Solanum species

21 from arid Australia was higher at $28^{\circ} \mathrm{C}$ compared with $12^{\circ} \mathrm{C}$ and $20^{\circ} \mathrm{C}$.

23 Therefore, the aim of this study was to develop an understanding of germination and

24 dormancy characteristics for an indicative range of eight Solanum species with

25 restoration and commercial value from the arid and semi-arid zone of Australia.

26 Specifically, for each species we determined (a) the seed and embryo morphology, (b)

27 whether seeds were permeable and able to imbibe water (via imbibition studies) and (c)

28 the effects and interactions of incubation temperature, gibberellic acid $\left(\mathrm{GA}_{3}\right)$,

29 karrikinolide $\left(\mathrm{KAR}_{1}\right)$ and smoke water $(\mathrm{SW})$ on seed germination.

\section{$31 \quad$ Materials and methods}

32 Seed collection

33 Table 1 shows the collection date, location and region for the eight Solanum species used

34 in this study. The method of seed cleaning and storage conditions varied between

35 species. Following collection of fruits of S. cunninghamii, S. dioicum, S. phlomoides and 
1 S. sturtianum, seeds were extracted from fruits and air dried and stored at $-18^{\circ} \mathrm{C}$ after

2 collection. Seeds were retrieved from storage in June 2006 and used in experiments

3 immediately.

5 Table 1. Collection date, location and Interim Biogeographic Regionalisation for 6 Australia (IBRA region) of eight Solanum species

\begin{tabular}{|c|c|c|c|}
\hline Species & Collection date & Location & IBRA region \\
\hline S. centrale & Feb 2007 & $\begin{array}{l}\text { Napperby Station, north of Alice Springs } \\
\left(\mathrm{S} 23^{\circ} 38^{\prime} 51^{\prime} \text { E } 133^{\circ} 51^{\prime} 50^{\prime \prime}\right)\end{array}$ & Burt Plain \\
\hline S. chippendalei & Aug 2005 & The Great Sandy Desert near Punju Njamal & $\begin{array}{l}\text { Great Sandy } \\
\text { Desert }\end{array}$ \\
\hline S. cunninghamii & 1993 & Between Millstream and Pannawonica & Pilbara \\
\hline S. dioicum & 1993 & $5.3 \mathrm{~km}$ on Shay Gap Road, near Marble Bar & Pilbara \\
\hline S. diversiflorum & Feb 2007 & $\begin{array}{l}\text { Telfer mine } \\
\left(\mathrm{S} 21^{\circ} 43^{\prime} 26^{\prime}, \mathrm{E} 122^{\circ} 12^{\prime} 33^{\prime \prime}\right) \text {. }\end{array}$ & $\begin{array}{l}\text { Great Sandy } \\
\text { Desert }\end{array}$ \\
\hline S. orbiculatum & Nov 2004 & $\begin{array}{l}\text { Shark Bay Salt Lease } \\
\left(\mathrm{S} 26^{\circ} 07^{\prime} 53.7^{\prime} \text { E } 113^{\circ} 22^{\prime} 58.5^{\prime \prime}\right)\end{array}$ & $\begin{array}{l}\text { Geraldton } \\
\text { Sandplains }\end{array}$ \\
\hline S. phlomoides & 1993 & $15 \mathrm{~km}$ south of Meekatharra & Murchison \\
\hline S. sturtianum & 2004 & $\begin{array}{l}\text { Lake Carey } \\
\left(\mathrm{S} 28^{\circ} 50^{\prime} 04^{\prime \prime} \text { E } 122^{\circ} 11^{\prime} 10^{\prime \prime}\right)\end{array}$ & Murchison \\
\hline
\end{tabular}

9 For $S$. orbiculatum, seeds were removed from freshly collected fruits using pectinase

$10(1 \%)$ to dissolve the fleshy fruit. Seeds were then air dried and stored at ambient

11 laboratory conditions (c. $22^{\circ} \mathrm{C}, 50 \% \mathrm{RH}$ ) for three months prior to use in experiments in

12 2005. S. orbiculatum seeds used for additional experiments at constant temperatures of

$1310,15,20,25$ and $30^{\circ} \mathrm{C}$ were collected in November 2005, cleaned as described above

14 and stored at ambient laboratory conditions for four months prior to the experiment in

152006.

17 Fruits of $S$. chippendalei and $S$. diversiflorum were air dried then cracked open to remove

18 the seeds. Seeds were stored at ambient laboratory conditions (c. $\left.22^{\circ} \mathrm{C}, 50 \% \mathrm{RH}\right)$ after

19 collection for three months (S. chippendalei) and six weeks (S. diversiflorum) prior to use

20 in experiments in 2005 and 2007 respectively.

22 Seeds of Solanum centrale were provided by Alice Springs Desert Park. Experiments

23 were undertaken in April 2007. The method of cleaning is unknown.

25 Specimens of each species were lodged at the Kings Park and Botanic Garden

26 Herbarium. Voucher numbers are as follows; S. centrale (LCOM4), S. chippendalei

27 (LCOM2), S. cunninghamii (LSWE1488), S. dioicum (LSWE1429), S. diversiflorum 
$4 \quad$ Seed and embryo characteristics, viability testing and imbibition studies

5 Given the consistency of seed coat colour, the colour of the seed coat of each species was

6 recorded from a simple observation. Seed diameter was determined for three replicates

7 of 10 seeds. Seed weight was determined by weighing three replicates of 100 seeds and multiplied by 10 to estimate 1000 seed weight. A cut test was used to estimate the viability of the seeds prior to germination experiments. Three replicates of 20 imbibed seeds were cut in half and inspected for healthy embryonic tissue. Firm, white embryos

12 Results of the cut test were confirmed by using tetrazolium chloride (Moore 1972)

13 whereby seeds were cut in half and placed cut side down on germination test paper 14 irrigated with $1 \%$ tetrazolium chloride buffered to $\mathrm{pH} 7$ with a phosphate buffer $\left(\mathrm{KH}_{2} \mathrm{PO}_{4}\right.$ 15 and $\mathrm{Na}_{2} \mathrm{HPO}_{4}$ ). The embryos of dissected seeds were examined and classified according 16 to Martin (1946) and described as fully developed or underdeveloped (Baskin and Baskin $172004 b)$.

19 For each species three replicates of $\geq 0.03 \mathrm{~g}$ of seeds were weighed, placed on moist 20 germination test paper in Petri dishes for five minutes, patted dry with paper towel to 21 absorb water on the seed surface, then re-weighed. Seeds were returned to the moist 22 germination test paper and each replicate was weighed again after 2, 4, 6, 24, 48, 72 and $2396 \mathrm{~h}$. Seeds were kept at ambient laboratory conditions $\left(c .22^{\circ} \mathrm{C}, 50 \% \mathrm{RH}\right)$ for the 24 duration of the experiment. Percent water uptake was determined gravimetrically.

\section{Germination}

27 Seeds of all species were soaked for $24 \mathrm{~h}$ in solutions of $2.89 \mathrm{mM}$ gibberellic acid $\left(\mathrm{GA}_{3}\right)$ 28 (Sigma Aldrich, 90\% GA 3 ), smoke water (SW) (1:10 v/v), $0.67 \mu \mathrm{M}$ karrikinolide (the 29 butenolide, 3-methyl-2H-furo[2,3-c]pyran-2-one) or deionised water (control). SW was 30 prepared with straw using the process described by Dixon et al. (1995). Karrikinolide 31 was synthesised in pure form as described in Flematti et al. (2005). After soaking, seeds 32 were surface sterilised in $2 \%(\mathrm{w} / \mathrm{v})$ calcium hypochlorite $\left(\mathrm{Ca}(\mathrm{OCl})_{2}\right)$ for 30 mins, then 33 rinsed three times with sterilised deionised water. Afterwards, four replicates of 25 seeds 34 were placed in plastic Petri dishes $(90 \mathrm{~mm})$ on water agar $(0.7 \% \mathrm{w} / \mathrm{v})$ and incubated at a $3512 / 12 \mathrm{~h}$ alternating temperature regime of $33 / 18^{\circ} \mathrm{C}$ or $26 / 13^{\circ} \mathrm{C}$. These two temperatures 
1 approximate summer and winter temperatures in the arid environment of Western

2 Australia where these plants commonly occur. In addition, three replicates of 10 seeds of

3 all species were nicked by removing the portions of seed coat and endosperm covering

4 the radicle tip. Nicked seeds were then incubated only at $33 / 18^{\circ} \mathrm{C}$ as described above.

6 In a second germination experiment, additional incubation temperatures of $10,15,20,25$

7 and $30^{\circ} \mathrm{C}$ were examined for $S$. orbiculatum and $S$. centrale seeds, but could not be

8 performed on the other species due to limited seed numbers. For all experiments, Petri

9 dishes were sealed with plastic (food grade cling film), then wrapped in aluminium foil to

10 exclude light. Foil was removed each time germination was recorded in the laboratory

11 under ambient light conditions. Germination of intact seeds was defined as the

12 emergence of the radicle and germination of nicked seeds was defined as the elongation

13 of the radicle tip, the production of root hairs and subsequent development into a normal

14 seedling. Germination was assessed five days a week for 2 weeks, then weekly until

15 germination had ceased. Final percentage germination data are presented for the first

16 experiment, and both final percentage germination and time to $50 \%$ of the final

17 germination data are presented for the second experiment.

19 Statistical analysis

20 Germination percentages were arcsine transformed prior to analysis. Data analysis was

21 performed on individual species to determine temperature and treatment differences

22 however, data from germination of nicked seeds were not included in this analysis.

23 Germination data were analysed by analysis of variance (ANOVA) $(P=0.05)$ using

24 Genstat 8.1 (Copyright 2005, Lawes Agricultural Trust). If significant differences were

25 detected by ANOVA, Fishers LSD was used to determine treatment differences. Due to

26 missing values, the control treatment was not included in the analysis of time to $50 \%$

27 germination of S. centrale.

\section{Results}

30 Seed and embryo characteristics, viability testing and imbibition studies

31 Four species had dark (black/dark brown) seed coats including the larger massed species

32 S. chippendalei, S. diversiflorum and S. sturtianum and the remaining four had light

33 (white/cream) seed coats (Table 2). Seed diameter ranged from $2.1-4.7 \mathrm{~mm}$. Seed

34 viability was generally high with the three lower massed species exhibiting $100 \%$

35 viability. S. chippendalei had the lowest viability at $73 \%$ (Table 2 ). The seeds of all 
1 eight species were endospermic and contained curved linear embryos. The curved

2 embryo was longer than the seed and was fully developed. Seeds of all species readily

3 imbibed water (Fig. 1). Increase in seed mass due to water uptake over $48 \mathrm{~h}$ ranged from

$4 \quad 17 \%$ (S. dioicum) to $46 \%$ (S. chippendalei).

6 Table 2. Seed coat colour, seed diameter, seed weight and viability (Mean $\pm \mathrm{SE})$ of 7 eight Solanum species.

\begin{tabular}{|c|c|c|c|c|}
\hline Species & Seed coat colour & $\begin{array}{l}\text { Seed diameter } \\
(\mathrm{mm})\end{array}$ & $\begin{array}{l}\text { Weight of } \\
1000 \text { seeds }(\mathrm{g})\end{array}$ & $\begin{array}{l}\text { Viability } \\
(\%)\end{array}$ \\
\hline S. centrale & Light & $2.8 \pm 0.04$ & $2.4 \pm 0.02$ & $88 \pm 5 \%$ \\
\hline S. chippendalei & Dark & $4.7 \pm 0.06$ & $7.8 \pm 0.10$ & $73 \pm 3 \%$ \\
\hline S. cunninghamii & Light & $2.1 \pm 0.02$ & $1.1 \pm 0.01$ & $100 \pm 0 \%$ \\
\hline S. dioicum & Dark & $2.1 \pm 0.04$ & $1.4 \pm 0.02$ & $100 \pm 0 \%$ \\
\hline S. diversiflorum & Dark & $4.0 \pm 0.01$ & $8.1 \pm 0.01$ & $96 \pm 3 \%$ \\
\hline S. orbiculatum & Light & $2.9 \pm 0.04$ & $2.2 \pm 0.03$ & $95 \pm 3 \%$ \\
\hline S. phlomoides & Light & $2.3 \pm 0.04$ & $1.4 \pm 0.02$ & $100 \pm 0 \%$ \\
\hline S. sturtianum & Dark & $3.0 \pm 0.03$ & $4.0 \pm 0.00$ & $78 \pm 2 \%$ \\
\hline
\end{tabular}

10 Germination

11 Whilst untreated (control) seeds of S. cunninghamii and S. phlomoides had less than $20 \%$

12 germination when incubated at $26 / 13^{\circ} \mathrm{C}$, germination was $97 \%$ and $62 \%$ respectively

13 when incubated at $33 / 18^{\circ} \mathrm{C}$ (Fig. 2 c,g). In contrast, untreated seeds of S. centrale, $S$.

14 dioicum and S. orbiculatum had only $1 \%-27 \%$ germination at both $26 / 13^{\circ} \mathrm{C}$ and $33 / 18^{\circ} \mathrm{C}$

15 (Fig. 2a,d,f). Seeds of S. diversiflorum did not germinate at $33 / 18^{\circ} \mathrm{C}$, but demonstrated

$162 \%$ germination when incubated at $26 / 13^{\circ} \mathrm{C}$ (Fig. 2e). Untreated seeds of S. chippendalei

17 and S. sturtianum failed to germinate at either temperature (Fig. 2b,h).

19 Treatment of seeds of all species with $\mathrm{GA}_{3}$ significantly increased $(P<0.05)$ germination,

20 compared with the controls, at either one or both temperature regimes (Fig. 2). GA

21 promoted germination of $S$. cunninghamii at $26 / 13^{\circ} \mathrm{C}$, but when incubated at $33 / 18^{\circ} \mathrm{C}$

22 germination of both control and $\mathrm{GA}_{3}$ treated seeds was $>95 \%$ (Fig. 2c). $\mathrm{GA}_{3}$

23 significantly increased $(P<0.05)$ germination of $S$. phlomoides at $26 / 13^{\circ} \mathrm{C}$, but

24 suppressed germination at $33 / 18^{\circ} \mathrm{C}$ (Fig. $2 \mathrm{~g}$ ). For the other six species, $\mathrm{GA}_{3}$ significantly

25 increased $(P<0.05)$ germination at both $26 / 13^{\circ} \mathrm{C}$ and $33 / 18^{\circ} \mathrm{C}$ (Fig. 2a,b,d,e,f,h). For

26 most species germination of $\mathrm{GA}_{3}$ treated seeds was similar at both temperatures, although

27 S. orbiculatum seeds germinated to a higher percentage at $33 / 18^{\circ} \mathrm{C}$ than at $26 / 13^{\circ} \mathrm{C}$

$28(P<0.05)\left(\right.$ Fig. 2f) and $S$. centrale germinated to a higher percentage at $26 / 13^{\circ} \mathrm{C}$ than at

$2933 / 18^{\circ} \mathrm{C}(P<0.05)$ (Fig. 2a). 
1 Unlike $\mathrm{GA}_{3}$, SW promoted germination in some, but not all species. SW significantly

2 increased $(P<0.05)$ germination of $S$. centrale, $S$. dioicum and $S$. orbiculatum relative to

3 the control at both temperature regimes (Fig. 2a,d,f). For seeds of S. cunninghamii, SW

4 increased germination at $26 / 13^{\circ} \mathrm{C}$ but suppressed it at $33 / 18^{\circ} \mathrm{C}$ (Fig. $2 \mathrm{c}$ ).

5 For $S$. phlomoides seeds, SW did not affect germination at $26 / 13^{\circ} \mathrm{C}$, but suppressed

6 germination at $33 / 18^{\circ} \mathrm{C}$ (Fig. $2 \mathrm{~g}$ ). For the remaining three species $S$. chippendalei, $S$.

7 diversiflorum and S. sturtianum, germination of SW treated seeds was negligible (Fig.

$82 \mathrm{~b}, \mathrm{e}, \mathrm{h})$.

10 Karrikinolide elicited higher germination than control seeds for five species at one or

11 both incubation temperatures $(P<0.05)$. Karrikinolide increased germination of $S$.

12 dioicum and $S$. orbiculatum to at least the same level as $\mathrm{GA}_{3}$ and $\mathrm{SW}$ at both incubation

13 temperatures (Fig. 2d,f). For S. centrale seeds, germination of karrikinolide treated seeds

14 exceeded that of control and SW treated seeds at both incubation temperatures (Fig. 2a).

15 Germination of S. cunninghamii and S. phlomoides was promoted by karrikinolide at

$1626 / 13^{\circ} \mathrm{C}$ but not at $33 / 18^{\circ} \mathrm{C}$ (Fig. $2 \mathrm{c}, \mathrm{g}$ ). For the remaining three species (S. chippendalei,

17 S. diversiflorum and S. sturtianum) germination in the presence of karrikinolide was $<5 \%$

18 (Fig. 2b,e,h). Coincidently, these three species all had dark seed coats, and had larger

19 seeds (1000 seeds $\geq 4.0 \mathrm{~g})$ compared with the other five species (1000 seeds $\leq 2.4 \mathrm{~g})$

20 (Table 2).

22 Nicking seeds did not elicit germination of S. chippendalei, S. diversiflorum or $S$.

23 sturtianum (Fig. 2b,e,h). Nicking seeds of S. centrale, S. dioicum and S. orbiculatum

24 increased germination relative to the control, and to similar levels as seeds treated with

$25 \mathrm{GA}_{3}$, SW or karrikinolide (Fig. 2a,d,f). Nicked seeds of S. cunninghamii germinated to

26 the same percent as control seeds but those of $S$. phlomoides germinated to only half the

27 percentage of control seeds (Fig. 2c,g).

29 Additional experiments were undertaken on S. centrale and S. orbiculatum to examine

30 the effects of incubation temperature in greater detail. As in the first experiment, control

31 germination of $S$. centrale seeds was very low $(<2 \%)$ across all incubation temperatures.

32 Germination of seeds treated with $\mathrm{GA}_{3}$ was high (81-99\%) between $10-25^{\circ} \mathrm{C}$, but lower

33 at $30^{\circ} \mathrm{C}(65 \%)$ (Fig. 3a). Similarly, germination of seeds treated with SW and

34 karrikinolide was slightly higher at 10,15 and $20^{\circ} \mathrm{C}(7-35 \%)$, compared with at 25 and

$3530^{\circ} \mathrm{C}(<5 \%)(P<0.05)$. Germination of seeds treated with karrikinolide was lower at the 
1 constant incubation temperatures compared with the alternating temperatures of 26/13

2 and $33 / 18^{\circ} \mathrm{C}(63-84 \%)(P<0.05)$. Although germination of $\mathrm{GA}_{3}, \mathrm{SW}$ and karrikinolide

3 treated seeds of $S$. centrale incubated at $10^{\circ} \mathrm{C}$ was significantly higher $(P<0.05)$ than at

$430^{\circ} \mathrm{C}$, time to $50 \%$ germination was much longer (Fig. $3 \mathrm{c}$ ). At $10^{\circ} \mathrm{C}$, time to $50 \%$

5 germination was around $22-24$ days, compared with $2-6$ days at $30^{\circ} \mathrm{C}$. Time to $50 \%$

6 germination did not differ from 15 to $30^{\circ} \mathrm{C}$.

7

8 For $S$. orbiculatum, germination percentage of control seeds increased as the temperature

9 increased (Fig. 3b). All treatments significantly increased germination $(P<0.05)$ relative

10 to the control at each temperature. Germination of $\mathrm{GA}_{3}$ and $\mathrm{SW}$ treated seeds was higher

11 at 20, 25 and $30^{\circ} \mathrm{C}$ compared with 10 and $15^{\circ} \mathrm{C}(P<0.05)$, whereas karrikinolide treated

12 seeds had high germination (90-98\%) across all temperatures. These treatments also

13 increased the rate of germination $(P<0.05)$ (i.e. decreased the time to $50 \%$ germination)

14 compared with the control at all temperatures (Fig. 3d). In addition, the time to 50\%

15 germination decreased as the incubation temperature increased, with the fastest

16 germination observed at 20, 25 and $30^{\circ} \mathrm{C}$ (Fig. 3d). 


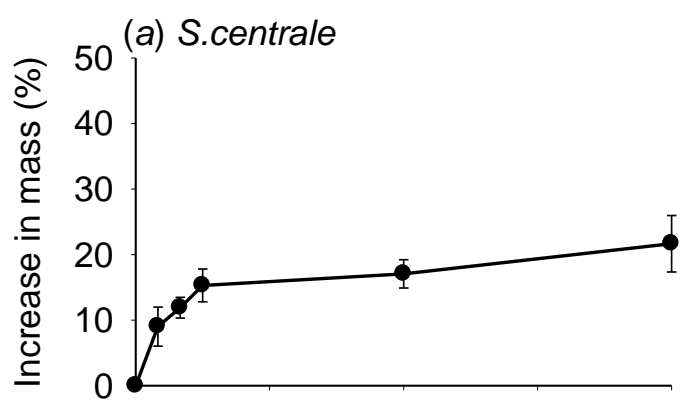

(b) S. chippendalei
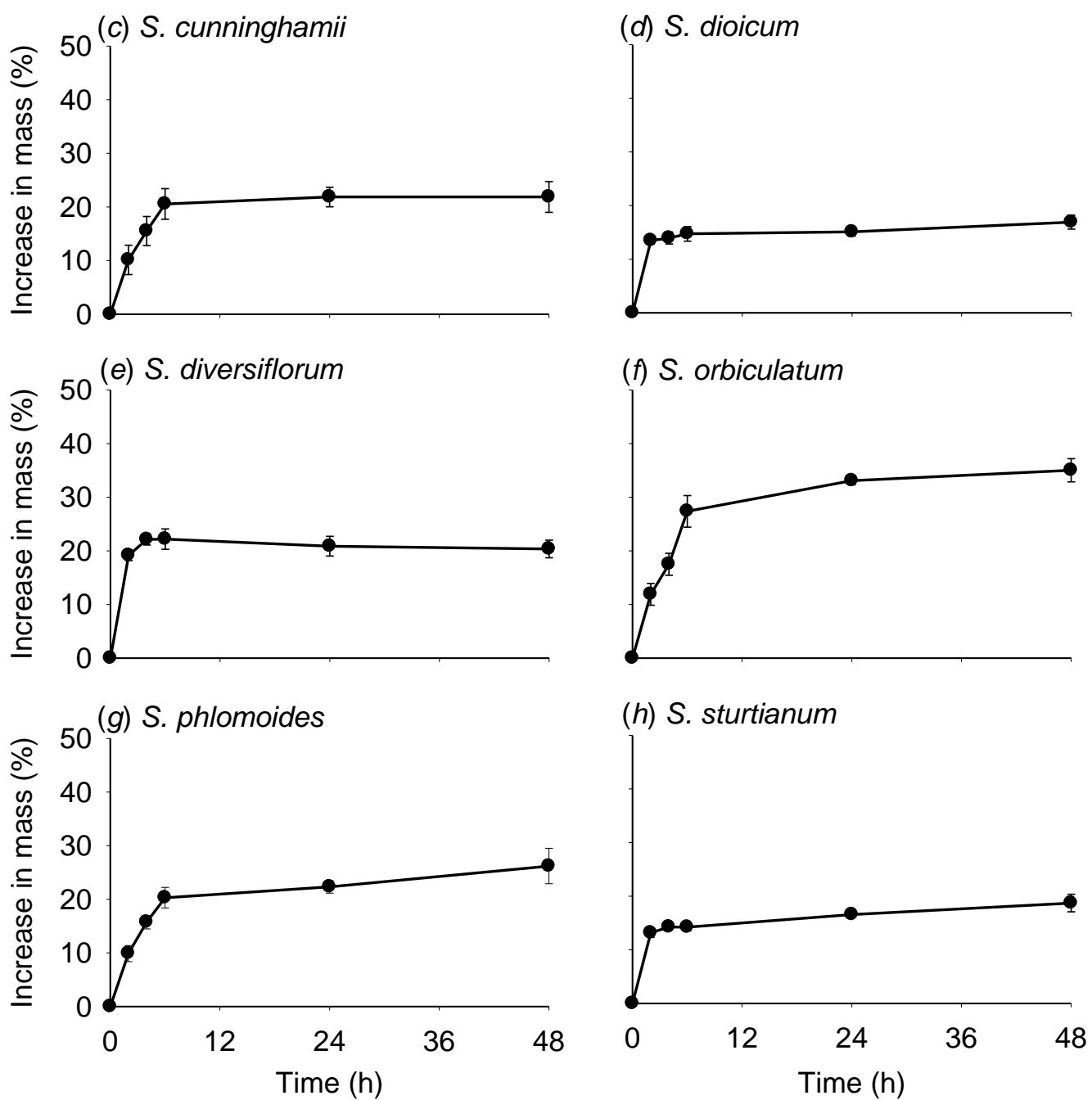

Fig. 1. Imbibition (\% water uptake) of eight Solanum species over $48 \mathrm{~h}$ at room temperature (c. $22^{\circ} \mathrm{C}$ ) (a) Solanum centrale, (b) S. chippendalei, (c) S. cunninghamii, $(d)$ S. dioicum, (e) S. diversiflorum, (f) S. orbiculatum, (g) S. phlomoides, and ( $h$ ) S.

5 sturtianum. Bars indicate standard error 
(a) S. centrale

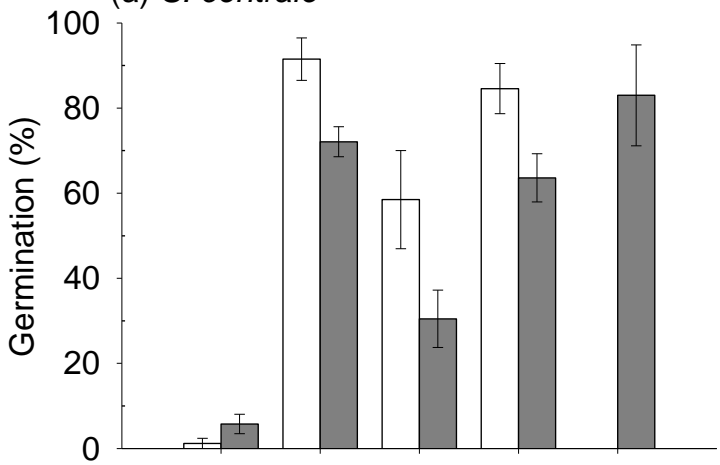

(c) S. cunninghamii

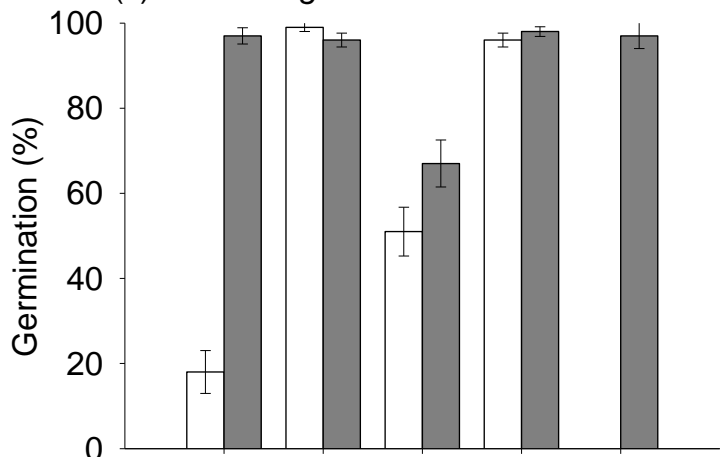

(e) S. diversiflorum

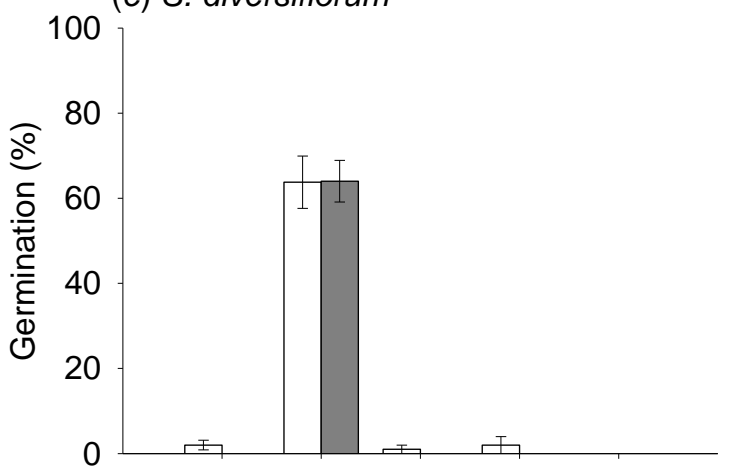

(g) S. phlomoides

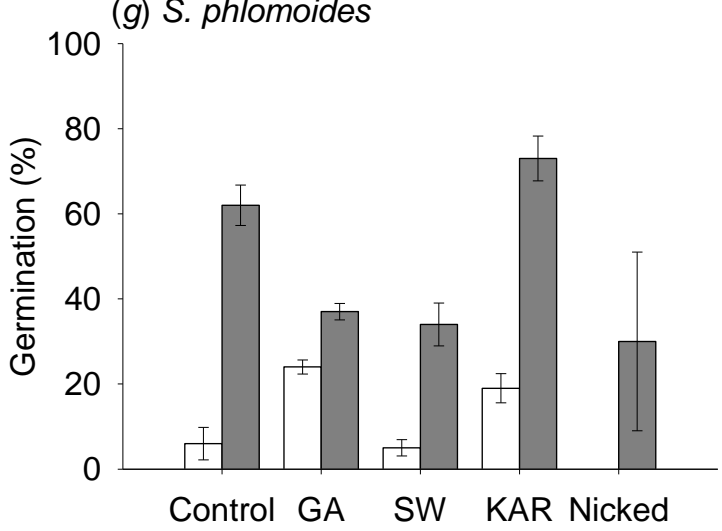

(b) S. chippendalei

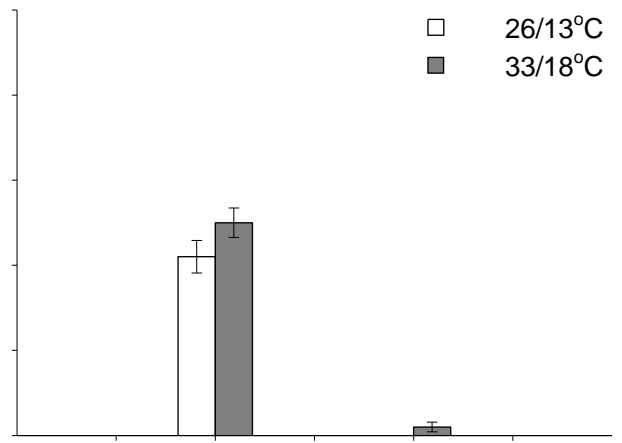

(d) S. dioicum

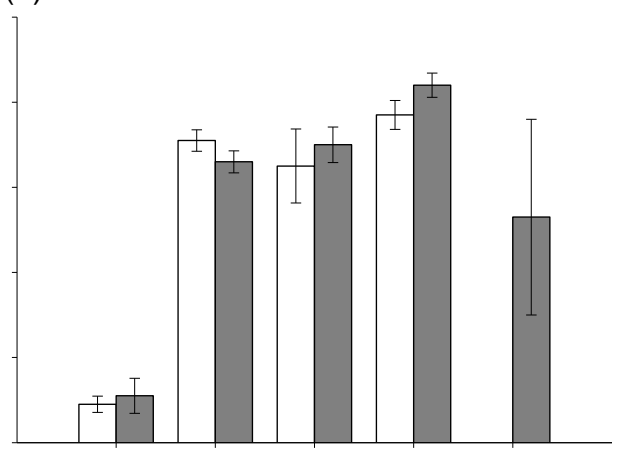

(f) S. orbiculatum

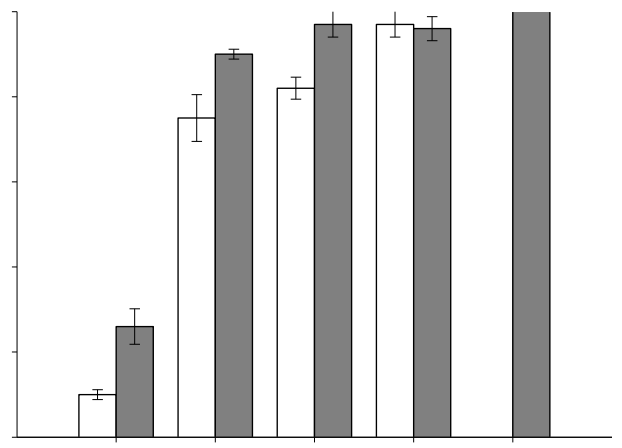

(h) S. sturtianum

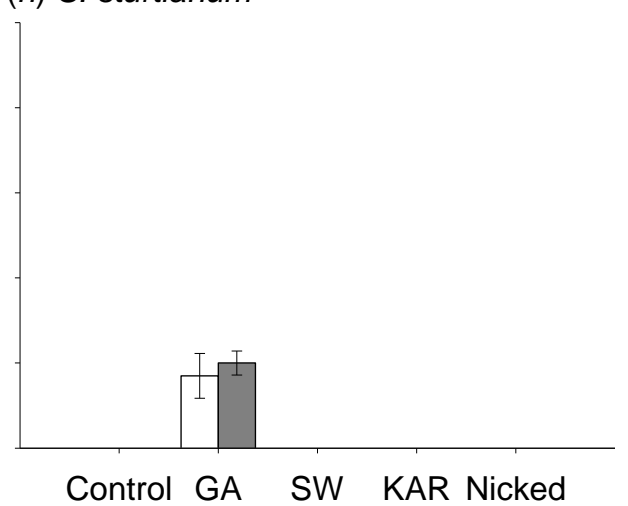

Fig. 2. Mean ( \pm SE) germination (radicle emergence) of (a) Solanum centrale, $(b) S$. chippendalei, (c) S. cunninghamii, (d) S. dioicum, (e) S. diversiflorum, (f) S. orbiculatum, (g) S. phlomoides, and (h) S. sturtianum. Seeds were soaked for $24 \mathrm{~h}$ in water (Control), in gibberellic acid (GA), in smoke water (SW), karrikinolide (KAR) or nicked, and incubated at $12 / 12 \mathrm{~h}$ alternating temperature regime of $26 / 13^{\circ} \mathrm{C}$ or $33 / 18^{\circ} \mathrm{C}$ (Nicked treatment only incubated at $33 / 18^{\circ} \mathrm{C}$ ). 

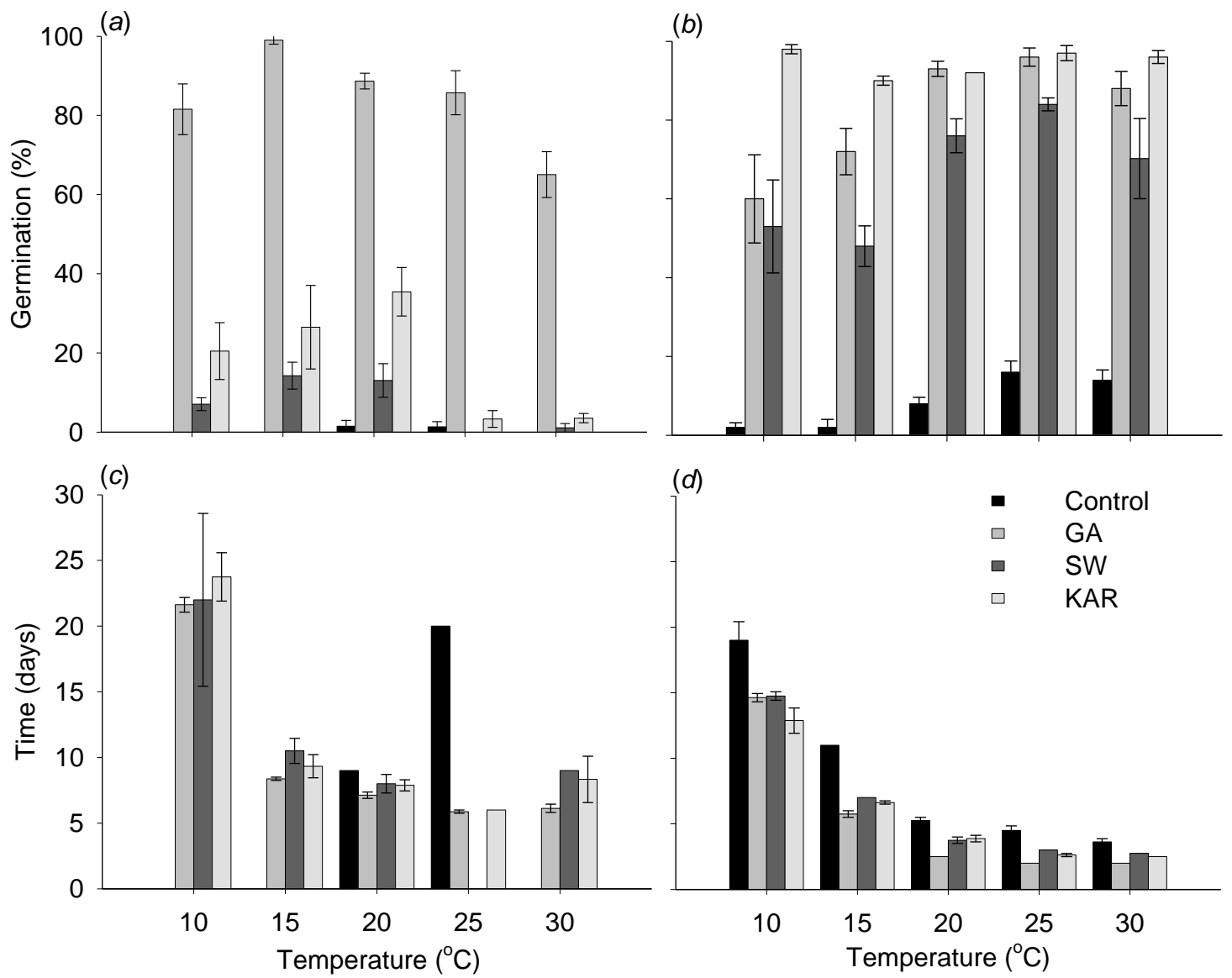

Fig 3. Mean ( \pm SE) germination of (a) Solanum centrale and (b) S. orbiculatum and time to $50 \%$ of the final germination of (c) S. centrale and (d) S. orbiculatum seeds treated with water (control), gibberellic acid (GA), smoke water (SW) and karrikinolide (KAR) and incubated at constant temperatures of $10,15,20,25$ and $30^{\circ} \mathrm{C}$.

\section{Discussion}

Germination was increased in all Solanum species at one or both incubation temperatures using germination-promoting compounds and these results provide some direction for more efficient methods for rehabilitation and commercial production. The degree to

11 which each compound was effective varied somewhat between species, probably due to

12 differing germination and dormancy characteristics and different seed ages and storage

13 histories. Some species germinated without treatment, whereas germination in others

14 was stimulated by SW, karrikinolide or $\mathrm{GA}_{3}$. Firstly, germination of untreated seeds of

15 two species (S. cunninghamii and S. phlomoides) was moderate to high at the incubation 16 temperature $33 / 18^{\circ} \mathrm{C}$. It is possible that these two species are either non-dormant or they 17 may have after ripened between collection and storage (the time and conditions between 18 collection and storage are unknown), hence dormancy may have been partly or fully

19 overcome. Secondly, species that exhibited little or no germination of untreated seeds ( $S$. 20 centrale, S. chippendalei, S. dioicum, S. diversiflorum, S. orbiculatum and S. sturtianum) 21 could be considered dormant (i.e. do not germinate within a period of time (30 days) 
when provided with normal physical environmental factors (Baskin and Baskin 2004b)).

2 However, species where control germination was low, but germination of SW or

3 karrikinolide treated seeds was high (S. centrale, S. dioicum and S. orbiculatum), may not

4 be dormant, if smoke products are considered as agents that promote germination

5 independently of dormancy status as suggested by some studies (Baker et al. 2005;

6 Merritt et al. 2007; Rokich and Dixon 2007). For the three species where germination of

7 control, SW and karrikinolide treated seeds of S. chippendalei, S. diversiflorum and $S$. sturtianum was low or zero, but germination was promoted by $\mathrm{GA}_{3}$, the presence of dormancy is likely, although this can not be concluded absolutely as germination was

12 If seeds are dormant, it is useful to know what type of dormancy they exhibit. Imbibition 13 studies indicated that seeds of all species readily take up water thus do not exhibit 14 physical or combinational dormancy. Observing seed morphology of all species showed that the embryos were differentiated and fully developed indicating that the seeds do not exhibit morphological or morphophysiological dormancy. As four classes of dormancy have been ruled out, dormant species must therefore exhibit physiological dormancy.

19 Germination promotion by smoke in the Australian flora is well established (Dixon et al. 20 1995; Roche et al. 1997) and the active compound in smoke, a butenolide, now know as 21 karrikinolide, has been recently discovered to promote germination of a range of smoke responsive species from a wide variety of ecosystems including arid regions (Flematti et al. 2004; Merritt et al. 2006; Stevens et al. 2007). The results of the present study contrast with two other studies on S. centrale; one finding neither SW or aerosol smoke effective at promoting germination (Stefaniski 1998) and the other finding aerosol smoke only increased germination after seeds were nicked (Ahmed et al. 2005). A difference in smoke responsiveness could be due to collection of $S$. centrale at different locations and in different years. For example, Stevens et al. (2007) found a difference in butenolide (karrikinolide) response of Brassica tournefortii depending on collection year and

31 half of the species (including S. centrale). Notably, germination of karrikinolide treated

32 seeds of four species (S. centrale, S. cunninghamii, S. orbiculatum and S. phlomoides)

33 was higher than that of SW treated seeds at one or both incubation temperatures.

34 Increased germination in the presence of karrikinolide, as compared to SW, was also 35 found in a study on Australian Asteraceae (Merritt et al. 2006) and this was explained by 
the presence of possible toxic compounds in SW. Similar evidence for toxicity issues with SW have been noted by Flematti et al. (2004) who found that undiluted SW reduced germination of Conostylis aculeata and Stylidium affine compared with a 1 in 10 dilution.

5 For the three species where SW and karrikinolide failed to elicit germination $(S$.

6 chippendalei, S. diversiflorum and S. sturtianum - which had dark seed coats and the

7 largest seeds), the seeds are either not smoke-responsive, or dormancy must be overcome

8 before the seeds become smoke-responsive. Seeds of two of these species were fresh

9 when experiments commenced, and the other had been stored for two years at $-18^{\circ} \mathrm{C}$,

10 suggesting these seeds may not have been sensitive to the smoke cue. In some studies,

11 freshly collected seeds have been found to be insensitive to smoke. For example, seeds

12 of some species are more responsive to smoke after dormancy has been released by dry

13 after-ripening (Tieu et al. 2001a) warm stratification (Merritt et al. 2007) or soil burial

14 (Tieu et al. 2001b; Baker et al. 2005). Although germination of these three Solanum

15 species was not stimulated by SW or karrikinolide, it was stimulated by $\mathrm{GA}_{3}$. This

16 observation indicates that seeds of the study species exhibit physiological dormancy, as

17 GA has been observed to promote germination of other physiologically dormant seeds

18 (Baskin and Baskin 1998; Baskin and Baskin 2004b). However, nicking (scarification) is

19 also known to promote germination of seeds with non-deep physiological dormancy, as

20 the embryos within these seeds lack the growth potential to emerge through their

21 covering structures (Groot and Karssen 1987; Baskin and Baskin 1998; Baskin and

22 Baskin 2004b). In this study, nicking did not promote germination of S. chippendalei, S.

23 diversiflorum and $S$. sturtianum suggesting that germination control is not simply via

24 mechanical restraint to embryo growth imposed by the seed coat. It is therefore possible

25 that the seeds of these three species exhibit intermediate physiological dormancy as in

26 these types of seeds scarification does not overcome dormancy, but GA promotes

27 germination (Baskin and Baskin 2004b).

29 Dormancy of $S$. centrale was recently classified by Ahmed et al. (2005). Like our study, 30 these authors found that germination of $S$. centrale seeds was promoted by nicking. They

31 inferred from this result that the seeds had a water impermeable seed coat and that the 32 species exhibited seed coat imposed dormancy. However, imbibition was not tested to 33 determine whether or not the seeds imbibed water prior to nicking. As our study found 34 all eight Solanum species readily imbibed, S. centrale seeds have a water permeable seed coat and do not possess physical dormancy. Two recent studies (Baskin and Baskin 
2004b; Baskin et al. 2006) have emphasised that mechanical scarification promotes germination of both physically and physiologically dormant seeds, and that some studies have incorrectly identified physical dormancy based on increased germination of

4 scarified seeds, highlighting the importance of imbibition testing for identification of

5 dormancy states.

Although there were some subtle differences between germination at $26 / 13^{\circ} \mathrm{C}$ and $33 / 18^{\circ} \mathrm{C}$, for most species broadly similar responses at these two temperatures were evident. In addition, karrikinolide treated seeds of $S$. orbiculatum germinated to a high percentage over the temperature range of 10 to $30^{\circ} \mathrm{C}$. This apparent broad temperature

11 range for germination suggests that some Solanum species may be able to germinate

12 throughout the year, responding to moisture cues rather than temperature cues (within

13 their normal seasonal range), and enabling germination at any time during the year

14 (Ahmed et al. 2005). In a study on germination of central Australian plants, Jurado and

15 Westoby (1992) found that $30 \%$ of species tested did not show a preference for

16 germination temperature, although S. quadriloculatum had higher germination at $28^{\circ} \mathrm{C}$

17 compared with 20 and $12^{\circ} \mathrm{C}$. The range over which the Solanum species germinated in

18 this study was generally higher than that of species from the south west of Australia

19 which have optimal germination between 13 and $20^{\circ} \mathrm{C}$ (Bell 1999). In addition, time to

$2050 \%$ germination of $S$. orbiculatum decreased as the temperature increased. These

21 results will be important to those propagating Solanum species for restoration and

22 commercial production, particularly if propagation is to occur in areas outside the normal

23 range of the species.

25 In conclusion, this study has observed that $\mathrm{SW}$, karrikinolide and/or $\mathrm{GA}_{3}$ can promote

26 germination of eight Solanum species, the degree to which differs between species.

27 Seeds of some species may be dormant, and given that Solanum seeds have fully

28 developed embryos and seeds readily take up water, it is likely that dormancy is

29 physiological. This study also offers some insight into preferred germination

30 temperatures. The information about germination will be useful for propagation of

31 Solanum species for horticulture or restoration.

\section{Acknowledgements}

34 Seed of $S$. centrale was kindly donated by Alice Springs Desert Park and seed of $S$.

35 chippendalei was kindly donated by Kim Courtenay of Broome TAFE. Thanks go to Jeff 
1 Walck for his comments to improve the manuscript. Thanks also go to Bronwynne York

2 for technical support. Funding for this research was provided by Shark Bay Salt whose

3 staff also provided logistical support for the collection of some seeds used in this study.

4 In addition, L. Commander received a post-graduate scholarship from the Minerals and

5 Energy Research Institute of Western Australia.

6

7 References

8 Ahmed AK, Johnson KA (2000) Horticultural development of Australian native edible

9 plants. Australian Journal of Botany 48, 417-426.

11 Ahmed AK, Johnson KA, Burchett MD, Kenny BJ (2005) The effects of heat, smoke,

12 leaching, scarification, temperature and $\mathrm{NaCl}$ salinity on the germination of Solanum

13 centrale (the Australian bush tomato). Seed Science and Technology 34, 33 - 45.

15 Baker KS, Steadman KJ, Plummer JA, Merritt DJ, Dixon KW (2005) The changing

16 window of conditions that promotes germination of two fire ephemerals, Actinotus

17 leucocephalus (Apiaceae) and Tersonia cyathiflora (Gyrostemonaceae). Annals of

18 Botany 96, 1225-1236.

20 Baskin CC, Baskin JM (1998) 'Seeds: ecology, biogeography and evolution of dormancy

21 and germination.' (Academic Press: San Diego, USA)

23 Baskin CC, Baskin JM (2004a) Germinating seeds of wildflowers, an ecological

24 perspective. HortTechnology 14, $467-473$.

26 Baskin CC, Thompson K, Baskin JM (2006) Mistakes in germination ecology and how 27 to avoid them. Seed Science Research 16, 165-168.

29 Baskin JM, Baskin CC (2004b) A classification system for seed dormancy. Seed Science

30 Research 14, 1-16.

32 Bell DT (1999) The process of germination in Australian species. Australian Journal of 33 Botany 47, 475-517. 
1 Bell DT, King LA, Plummer JA (1999) Ecophysiological effects of light quality and

2 nitrate on seed germination in species from Western Australia. Australian Journal of

3 Ecology 24, 2-10.

5 Bell DT, Plummer JA, Taylor SK (1993) Seed germination ecology in southwestern

6 Western Australia. Botanical Review 59, $24-73$.

8 Bell DT, Rokich DP, McChesney CJ, Plummer JA (1995) Effects of temperature, light

9 and gibberellic acid on the germination of seeds of 43 species native to Western

10 Australia. Journal of Vegetation Science 6, 797-806.

12 Debeaujon I, Koornneef M (2000) Gibberellin requirement for Arabidopsis seed

13 germination is determined both by testa characteristics and embryonic abscisic acid.

14 Plant Physiology 22, 415-424.

16 Dixon KW, Merritt DJ, Flematti GR, Ghisalberti EL (2008) Karrikinolide - a

17 phytoreactive compound derived from smoke with applications in horticulture, ecological

18 restoration and agriculture. Acta Horticulturae, in press.

20 Dixon KW, Roche S, Pate JS (1995) The promotive effect of smoke derived from burnt

21 native vegetation on seed germination of Western Australian plants. Oecologia 101, 185-

22192.

24 Flematti GR, Ghisalberti EL, Dixon KW, Trengove RD (2004) A compound from smoke 25 that promotes seed germination. Science 305, 977.

27 Flematti GR, Ghisalberti EL, Dixon KW, Trengove RD (2005) Synthesis of the seed 28 germination stimulant 3-methyl-2H-furo[2,3-c]pyran-2-one. Tetrahedron Letters 46, $29 \quad 5719-5721$.

31 Groot SPC, Karssen CM (1987) Gibberellins regulate seed germination in tomato by 32 endosperm weakening: a study with gibberellin-deficient mutants. Planta 171, 525-531. 
1 Groot SPC, Kieliszewska-Rokicka B, Vermeer E, Karseen CM (1988) Gibberellin-

2 induced hydrolysis of endosperm cell walls in gibberellin-deficient tomato seeds prior to

3 radicle protrusion. Planta $\mathbf{1 7 4}, 500-504$.

5 Jurado E, Westoby M (1992) Germination Biology of Selected Central Australian Plants.

6 Australian Journal of Ecology 17, 341-348.

8 Kucera B, Cohn MA, Leubner-Metzger G (2005) Plant hormone interactions during seed

9 dormancy release and germination. Seed Science Research 15, 281-307.

11 Latz P (1995) 'Bushfires and bushtucker: Aboriginal plant use in Central Australia.' (IAD

12 Press: Alice Springs)

14 Martin AC (1946) The comparative internal morphology of seeds American Midland

15 Naturalist 36, 513-660.

17 Merritt DJ, Kristiansen M, Flematti GR, Turner SR, Ghisalberti EL (2006) Effects of a

18 butenolide present in smoke on light-mediated germination of Australian Asteraceae.

19 Seed Science Research 16, 29-35.

21 Merritt DJ, Turner SR, Clarke S, Dixon KW (2007) Seed dormancy and germination

22 stimulation syndromes for Australian temperate species. Australian Journal of Botany

$23 \mathbf{5 5}, 336-344$.

25 Moore RP (1972) Tetrazolium staining for assessing seed quality. In 'Seed ecology :

26 proceedings of the Nineteenth Easter School in Agricultural Science'. University of

27 Nottingham. (Ed. W Heydecker) pp. 347-366. (London, Butterworths)

29 Paczkowsa G, Chapman AR (2000) 'The Western Australian flora: a descriptive

30 catalogue.' (Wildflower Society of Western Australia: Perth)

32 Plummer JA, Bell DT (1995) The effect of temperature, light and gibberellic acid $\left(\mathrm{GA}_{3}\right)$

33 on the germination of Australian everlasting daisies (Asteraceae, Tribe Inuleae).

34 Australian Journal of Botany 43, 93-102. 
1 Roche S, Koch JM, Dixon KW (1997) Smoke enhanced seed germination for mine

2 rehabilitation in the southwest of Western Australia. Restoration Ecology 5, 191-203.

3

4 Rokich DP, Dixon KW (2007) Recent advances in restoration ecology, with a focus on

5 the Banksia woodland and the smoke germination tool. Australian Journal of Botany $\mathbf{5 5}$,

$6 \quad 375-389$.

7

8 Stefaniski A (1998) Manipulating seed dormancy in bush tomato (Solanum centrale).

9 Honours thesis, The University of Sydney.

11 Stevens JC, Merritt DJ, Flematti GR, Ghisalberti EL, Dixon KW (2007) Seed

12 germination of agricultural weeds is promoted by the butenolide 3-methyl- $2 \mathrm{H}$-furo[2,3-

13 c]pyran-2-one under laboratory and field conditions. Plant \& Soil 298, 113-124.

14

15 Tieu A, Dixon KW, Meney KA, Sivasithamparam K (2001a) The interaction of heat and

16 smoke in the release of seed dormancy in seven species from southwestern western

17 Australia. Annals of Botany 88, 259-265.

18

19 Tieu A, Dixon KW, Meney KA, Sivasithamparam K (2001b) Interaction of soil burial

20 and smoke on germination patterns in seeds of selected Australian native plants. Seed

21 Science Research 11, 69-76.

22

23

24 